\title{
A Case of Paradoxical Vocal Fold Movement Due to Psychological Causes
}

\section{Dong Min Shin (D) and Gi Cheol Park (D)}

Department of Otorhinolaryngology-Head and Neck Surgery, Samsung Changwon Hospital, Sungkyunkwan University School of Medicine, Changwon, Korea

\section{정신적 요인에 의한 역설적 성대운동 1 예}

신동민, 박기철

성균관대학교 의과대학 삼성창원병원 이비인후과학교실

Paradoxical vocal fold movement (PVFM) is a dystonic laryngeal disorder characterized by involuntary vocal fold adduction during inspiration and/or expiration. PVFM is uncommon and may aggravate airway obstruction. And patients with PVFM have a specific etiology; therefore, treatment must be individualized and given immediately. We present a case of 63-year-old male presenting with intermittent dyspnea. After multidisciplinary workup, we presumed psychogenic PVFM and evaluated with speech-language pathologist and psychologist. In this report, we describe a rare case of psychogenic PVFM patient.

Keywords Vocal fold movement; Laryngoscopy; Psychotherapy.

\section{서 론}

후두는 기관의 입구에 있으면서 기관의 개폐와 기도 저항을 조절함으로써 기도의 기 류 변화를 조절할 수 있다. 평상적인 호흡 시에 성대의 움직임은 극히 제한적이나, 최대 흡기 시에는 흉골갑상근(sternothyroid muscle)과 흥골설골근(sternohyoid muscle), 그 리고 기관 등에 의해 후두가 하방으로 이동하게 되고, 가성대는 측방으로 편평하게 펴 지며, 진성대는 완전히 외전되어 기도를 최대한으로 열어 준다. 하지만 상기도의 구조 적 이상이 없는 경우에도 흡기 또는 비발성 호기 시에 성대의 발작적 내전이 관찰된다면 이를 역설적 성대운동으로 정의할 수 있다[1]. 역설적 성대운동은 대체로 만성적인 호흡 장애를 일으키나, 때로는 발작 시 기도 폐쇄로 인한 급성 호흡장애를 일으켜 기도 삽관 과 기관 절개술과 같은 신속한 치료가 필요한 경우도 있다[2,3]. 원인으로 성대근 작용 이상을 일으킬 수 있는 신경계 질환 및 위식도 역류 질환과 같은 비심리적 원인과 정신 질환과 같은 심리적 원인으로 나눌 수 있다[1,4]. 따라서 역설적 성대운동이 의심되는 환 자에서 적절한 치료를 위해 세심한 진단이 필요하다.

저자들은 간헐적으로 발작적인 호흡곤란 증상이 있는 환자에서 역설적 성대운동으로

\author{
Received June 16, 2021 \\ Revised August 20, 2021 \\ Accepted September 15, 2021
}

\section{Corresponding Author}

Gi Cheol Park, MD, PhD

Department of Otorhinolaryngology-

Head and Neck Surgery,

Samsung Changwon Hospital,

Sungkyunkwan University

School of Medicine,

158 Paryong-ro, Masanhoewon-gu,

Changwon 51353, Korea

Tel +82-55-233-5982

Fax $+82-55-233-5441$

E-mail uuhent@naver.com

\section{ORCID iDs}

Dong Min Shin (1)

https://orcid.org/0000-0002-5562-0771

Gi Cheol Park (D)

https://orcid.org/0000-0001-7346-8550

This is an Open Access article distributed under the terms of the Creative Commons Attribution Non-Commercial License (https://creativecommons.org/ licenses/by-nc/4.0) which permits unrestricted non-commercial use, distribution, and reproduction in any medium, provided the original work is properly cited. 
진단하였고, 심리적 원인이 의심되어 정신건강의학과 진료 후 공황장애 진단 하, 약 복용으로 호흡곤란 증상의 뚜렷한 호전 을 경험하였다. 심리적 질환으로 인한 역설적 성대운동은 비 교적 드물며, 국내에서는 이에 대한 보고된 바가 없기에 본 증 례를 소개하고 문헌고찰과 함께 보고하는 바이다.

\section{증 례}

63세 남자 환자가 2개월 전부터 있었던 발작적인 호흡곤란 과 호흡곤란 시 동반되는 애성을 주소로 내원하였다. 환자는 5 개월 전 흥통으로 본원 순환기내과에서 시행한 심전도 검사 상 $2: 1$ 방실차단으로 영구 심박동기 삽입술을 시행한 과거력 이 있었다. 이외에 천식, 신경계 질환, 정신 질환 등의 과거력 은 없었으며, 수술력 및 가족력에서 특이 사항은 없었다. 병력 상 이전에 심한 호흡곤란을 경험한 적은 없었으며, 2개월 전 부터 호흡곤란은 주 1 회 정도의 빈도로 발작적으로 발생하였 고 발생시 3-4시간 가량 지속되며 애성이 동반되었다고 하였 다. 진료 시 호흡곤란을 호소하지 않았으며 음성은 특별한 이 상이 없었다. 가슴 청진 시 협착음 없이 정상이었다. 후두경 검 사 상 흡기 시 양측 성대 모두 충분히 외전되었으며, 발성 시 정상적인 성대운동을 보였다(Fig. 1A). 피열연골 사이 점막의 비후 소견 외에 특이 소견은 보이지 않아, 인후두 역류 질환 의심하에 프로톤펌프억제제인 esomeprazole $20 \mathrm{mg}$ 투여를 시작하였다. 4주 간 추적 관찰하였으며 환자는 4주간 2회의 발작적 호흡곤란을 경험하였다. 병력상 역설적 성대운동 의심 하에 프로톤펌프억제제 치료 지속 및 음성치료를 시작하였 고, 호흡기 내과와 협진을 통하여 폐기능검사를 시행하였으 며 정상 소견을 보였다(Fig. 2). 후두근 기능을 확인하기 위한 후두 근전도 검사에서 이상 소견이 보이지 않아 양측 후두근
의 기능 이상을 배제할 수 있었다. 또한 신경계 질환을 배제하 기 위해 뇌 자기공명영상 검사를 시행하였으며, 주요 이상 소 견이 없음을 확인하였다. 환자는 음성 치료와 프로톤펌프억 제제 치료를 지속하며 경과를 보던 중 발작적 호흡곤란 증상 이 지속되며 간헐적인 가슴 답답함 증상이 있어 본원 순환기 내과에 입원하였다. 입원하여 ergonovine 유발검사를 포함한 관상동맥조영 검사에서 이상 소견은 없었고 심박동기 재점검 에서도 특이 소견은 관찰되지 않았다. 심장 기원의 가능성이

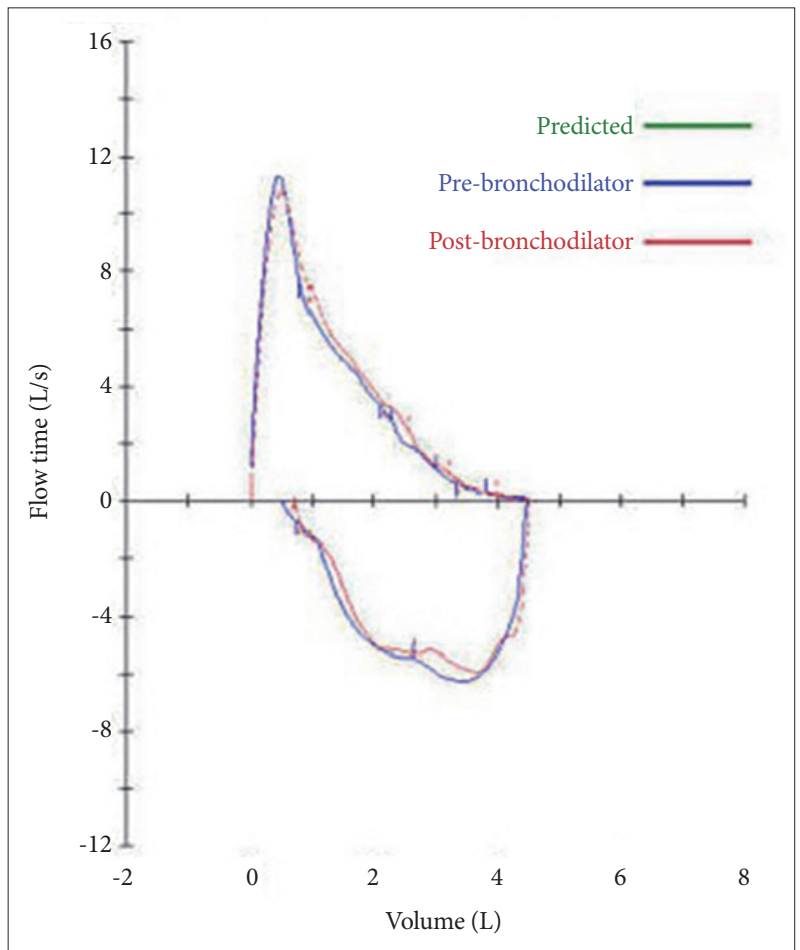

Fig. 2. Pulmonary function test results. Based on this flow-volume loop, there is no evidence of air-flow obstruction.
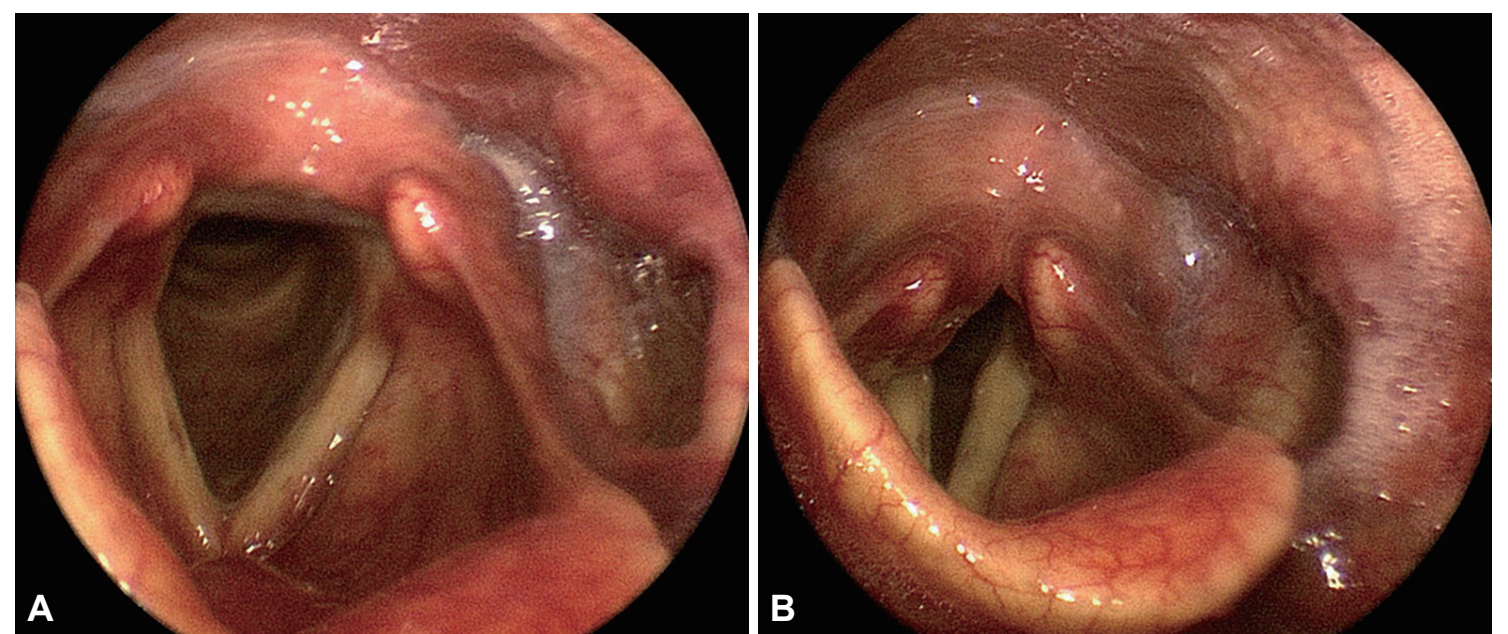

Fig. 1. Flexible laryngoscopic finding. A: Normal vocal cord abduction during inspiration in flexible laryngoscopy. B: Vocal cords during inspiration with paradoxical vocal cord motion disorder showing early paradoxical adduction and formation of posterior chink. 
배제되어 발작적 호흡곤란의 면밀한 관찰을 위해 이비인후과 로 전과되었다. 정서적 지지와 함께 음성 치료와 프로톤펌프 억제제 투여를 지속하였다. 입원 6일째 갑작스러운 호흡곤란 을 호소하였으며, 즉시 시행한 후두경 검사에서 호흡 시 양측 성대가 비정상적으로 내전하였고, 특히 흡기시에 두드러지게 관찰되었고 기도를 폐쇄하는 양상을 보여 최종적으로 역설적 성대운동으로 진단하였다(Fig. 1B). 정신적 원인을 배제하고 자 정신건강의학과와 협진을 고려하였으나 환자가 퇴원 후 연 고지 의원에서 진료를 원하여 입원 9일째 퇴원하였다. 환자는 퇴원 후 정신건강의학과 의원에 내원하여 불특정한 호흡 곤 란에 대한 심리적인 스트레스, 불안, 공포 반응 및 공황발작 이 확인되어 공황장애로 진단되었다. 치료를 위해 선택적 세 로토닌 재흡수 억제제인 escitalopram oxalate $20 \mathrm{mg}$ 을 복 용하며 이완요법 및 호흡훈련을 병행하였으며, 현저히 증상이 호전되어 일상적 생활이 가능하였다. 환자는 공황장애에 대 한 치료를 시작한지 6개월이 지난 현재까지 발작적 호흡곤란 이 없는 상태로 주기적으로 경과 관찰 중이다.

\section{고 찰}

역설적 성대운동은 상기도의 구조적 이상 없이 흡기나 비 발성 호기 시에 성대의 발작적 내전을 보이는 질환으로, 1974년 Patterson 등[1]에 의해 최초로 보고되었다. 증상은 여러 종류 로 발현되며, 주로 호흡곤란, 협착음, 애성 등이며 급성 발작 시에는 후두부 압박감을 나타내기도 한다[3-5]. 증상 발현이 극적인 경우 기관지 천식, 후두개염으로 잘못 진단되는 경우 가 있다[5]. 이 외에도 근긴장 이상, 위식도 역류질환, 감염, 성 대 마비, 폴립, 라인케 부종, 폴립 등과 같은 질환과 감별이 필 요하다[4,6].

역설적 성대운동은 신경계 또는 정신과적 질환으로 여겨지 며, 원인은 심리적인 경우와 비심리적인 경우로 구분할 수 있 다. 심리적인 원인은 우울증, 신체화/전환장애, 불안장애, 꾀병 과 같은 정신 질환이 주요 원인으로 생각된다[1,4]. 비심리적 원인은 뇌간 압박, 중증 대뇌 피질 손상, 하부 운동 신경세포 원 손상, 운동 질환과 같은 신경학적 이상을 고려해 볼 수 있 다. 가장 효과적인 진단 방법은 후두내시경 검사로[4], 자극을 최소화하고 생리적인 상태에서 관찰을 위해 굴곡 비후두내시 경 검사가 권장되며, 호흡시 성문부에 비정상적인 내전이 관 찰될 때 역설적 성대운동을 의심할 수 있다. 하지만 본 증례 처럼 간헐적인 발작 호흡곤란이 있는 경우 이상 소견을 확인 하기 어려운 점이 있다. 신경학적 질환의 가능성이 있으므로 뇌 자기공명영상 등의 검사를 통해 신경계 이상을 배제하는 것이 필수이다. 또한 폐기능 검사 및 기관지 내시경 검사를 통
해 천식과 감별할 수 있으며, 성대 근전도 검사는 갑상피열근 (thyroarytenoid muscle)의 활성화를 확인해 볼 수 있어 진 단에 도움이 된다[7]. 위식도 역류질환이 있는 경우 위산 역류 로 인해 성대의 과도한 긴장 및 경련이 유발될 수 있어 상부 위장관 내시경 및 24시간 $\mathrm{pH}$ 검사를 고려할 수 있다.

치료는 음성치료를 통한 보존적 요법이 일차적이며[8], 호 흡곤란의 증상은 보존적 치료만으로 호전되는 경우가 대부분 이다. 하지만 Altman 등[4]에 따르면 급작스럽게 심한 호흡곤 란이 발생하는 경우 기관 절개술 등을 통해 신속한 치료를 요 하기도 한다. 급성기에는 산소요법, 지속적 양압환기 등이 증 상 완화에 도움을 줄 수 있고, 만성기에는 생체 되먹이기 요법, 이완요법, 자가 최면요법이 도움이 된다[9]. 성대근의 이상이 있는 경우, 일측 혹은 양측 성대에 보툴리눔 독소 주사가 효 과적인 치료 방법이다[10].

역설적 성대운동은 심리적 및 비심리적인 다양한 병인이 연관되어 있어 세심한 진단이 필요하다. 본 증례처럼 간헐적 인 호흡곤란을 호소하는 환자에서, 검사 상 이상 소견이 없는 원인 불명인 경우 불특정한 호흡 곤란에 관한 불안, 공포 등 이 있는지 살펴보고, 정신 질환의 가능성을 염두에 두는 것이 치료 방향을 정하는데 중요하다고 생각된다. 저자들은 언어 치료사, 정신건강의학과 의사와 함께 역설적 성대운동 환자 를 평가하였으며 최종적으로 심리적 요인으로 인한 역설적 성 대운동으로 진단하고 치료하였기에 문헌고찰과 함께 이를 보 고하는 바이다.

중심 단어: 성대운동; 후두내시경 검사; 심리 치료.

Acknowledgments

None

Conflicts of Interest

The authors have no financial conflicts of interest.

Authors' Contribution

Conceptualization: Gi Cheol Park. Data curation: Dong Min Shin. Formal analysis: Dong Min Shin. Investigation: Dong Min Shin. Methodology: Gi Cheol Park. Project administration: Gi Cheol Park. Resources: Dong Min Shin. Supervision: Gi Cheol Park. Validation: Dong Min Shin. Visualization: Dong Min Shin. Writing_original draft: Dong Min Shin. Writing-review \& editing: Gi Cheol Park. Approval of final manuscript: all authors.

\section{REFERENCES}

1. Patterson R, Schatz M, Horton M. Munchausen's stridor: Non-organic laryngeal obstruction. Clin Allergy 1994;4(3):307-10.

2. Rogers JH, Stell PM. Paradoxical movement of the vocal cords as a cause of stridor. J Laryngol Otol 1978;92(2):157-8.

3. Dinulos JG, Karas DE, Carey JP, Del Beccaro MA. Paradoxical vocal cord motion presenting as acute stridor. Ann Emerg Med 1997;29(6): 815-7.

4. Altman KW, Mirza N, Ruiz C, Sataloff RT. Paradoxical vocal fold 
motion: Presentation and treatment options. J Voice 2000;14(1):99103

5. Newman KB, Mason UG 3rd, Schmaling KB. Clinical features of vocal cord dysfunction. Am J Respir Crit Care Med 1995;152(4 Pt 1): 1382-6.

6. Vertigan AE, Theodoros DG, Gibson PG, Winkworth AL. The relationship between chronic cough and paradoxical vocal fold movement: A review of the literature. J Voice 2006;20(3):466-80.

7. Hayes JP, Nolan MT, Brennan N, FitzGerald MX. Three cases of paradoxical vocal cord adduction followed up over a 10 -year period. Chest
1993;104(3):678-80

8. Colton R, Casper JK. Vocal rehabilitation. In: Colton R, Casper JK, editors. Understanding Voice Problems. 2nd ed. Baltimore: Williams \& Wilkins;1996. p.270-316.

9. Morris MJ, Deal LE, Bean DR, Grbach VX, Morgan JA. Vocal cord dysfunction in patients with exertional dyspnea. Chest 1999;116(6): 1676-82.

10. Blitzer A, Brin MF, Stewart CF. Botulinum toxin management of spasmodic dysphonia (laryngeal dystonia): A 12-year experience in more than 900 patients. Laryngoscope 1998;108(10):1435-41. 